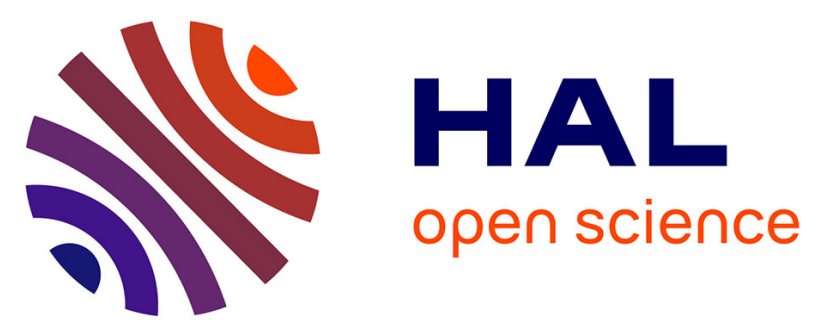

\title{
Comparative study of fatigue properties of Ti-6Al-4V specimens built by electron beam melting (EBM) and selective laser melting (SLM)
}

Victor Chastand, Philippe Quaegebeur, Wilson Maia, Eric Charkaluk

\section{- To cite this version:}

Victor Chastand, Philippe Quaegebeur, Wilson Maia, Eric Charkaluk. Comparative study of fatigue properties of Ti-6Al-4V specimens built by electron beam melting (EBM) and selective laser melting (SLM). Materials Characterization, 2018, 143, pp.76-81. 10.1016/j.matchar.2018.03.028 . hal-01828928

\section{HAL Id: hal-01828928 \\ https://hal.science/hal-01828928}

Submitted on 3 Aug 2021

HAL is a multi-disciplinary open access archive for the deposit and dissemination of scientific research documents, whether they are published or not. The documents may come from teaching and research institutions in France or abroad, or from public or private research centers.
L'archive ouverte pluridisciplinaire HAL, est destinée au dépôt et à la diffusion de documents scientifiques de niveau recherche, publiés ou non, émanant des établissements d'enseignement et de recherche français ou étrangers, des laboratoires publics ou privés. 


\title{
Authors :
}

Dr. Victor Chastand, Research Engineer

Thales Global Services, 19/21 avenue Morane Saulnier, 78140 Vélizy-Villacoublay,

France

Dr. Philippe Quaegebeur, Assistant Professor

Laboratoire de Mécanique de Lille (LML), CNRS, UMR 8107, Ecole Centrale de Lille, Cité Scientifique, 59655 Villeneuve d'Ascq, France

Dr. Wilson Maia, Research Engineer

Thales Global Services, 19/21 avenue Morane Saulnier, 78140 Vélizy-Villacoublay, France\}

Pr. Eric Charkaluk, CNRS Senior Research Scientist and Associate Professor (corresponding author)

Laboratoire de Mécanique des Solides (LMS), CNRS, UMR 7649, Ecole Polytechnique, 91128 Palaiseau Cedex, France

\begin{abstract}
:
Electron Beam Melting (EBM) and Selective Laser Melting (SLM) are two of the most developed powder bed fusion based additive manufacturing processes. In this paper, fatigue properties of Ti-6Al-4V specimens built by EBM and SLM are compared. Several parameters are assessed: processes, manufacturing direction, surface roughness, HIP treatment. Fatigue properties are analyzed in relation with the crack initiation mechanisms identified on each specimen's post-mortem micrographs. Machined specimens show better fatigue properties as surface defects are removed. HIP treatment improves fatigue properties by decreasing the defects size. Small differences in lifetime are observed between horizontal and vertical building directions because of different defect shapes regarding the loading axis. Finally, EBM and SLM parts have approximately the same fatigue properties, which are equivalent to conventional casting processes.
\end{abstract}

\section{Keywords :}

Ti-6Al-4V; Fatigue; Electron Beam Melting; Selective Laser Melting 


\section{Comparative study of fatigue properties of Ti-6Al-4V specimens built by electron beam melting (EBM) and selective laser melting (SLM)}

Victor Chastand, Thales Global Services, 19/21 avenue Morane Saulnier, 78140 VélizyVillacoublay, France

Dr. Philippe Quaegebeur, Laboratoire de Mécanique de Lille (LML), CNRS, UMR 8107, Ecole Centrale de Lille, Cité Scientifique, 59655 Villeneuve d'Ascq, France

Dr. Wilson Maia, Thales Global Services, 19/21 avenue Morane Saulnier, 78140 VélizyVillacoublay, France\}

Eric Charkaluk, Laboratoire de Mécanique des Solides (LMS), CNRS, UMR 7649, Ecole Polytechnique, 91128 Palaiseau Cedex, France

\section{Abstract}

Electron Beam Melting (EBM) and Selective Laser Melting (SLM) are two of the most developed powder bed fusion based additive manufacturing processes. In this paper, fatigue properties of Ti-6Al-4V specimens built by EBM and SLM are compared. Several parameters are assessed: processes, manufacturing direction, surface roughness, HIP treatment. Fatigue properties are analyzed in relation with the crack initiation mechanisms identified on each specimen's post-mortem micrographs. Machined specimens show better fatigue properties as surface defects are removed. HIP treatment improves fatigue properties by decreasing the defects size. Small differences in lifetime are observed between horizontal and vertical building directions because of different defect shapes regarding the loading axis. Finally, EBM and SLM parts have approximately the same fatigue properties, which are equivalent to conventional casting processes.

Key words: Ti-6Al-4V; Fatigue; Electron Beam Melting; Selective Laser Melting 


\section{Introduction}

Additive manufacturing ( $\mathrm{AM}$ ) processes consist in building parts layer by layer, starting from a 3D CAD model [1]. The first such manufacturing machines appeared in the 1980s and were mainly used to build plastic prototypes. Nowadays, the technology can be used to manufacture functional parts [2] and the industrialization of AM is now in place for metallic components.

These processes are useful in many fields, including the aerospace industry, as they allow the design and manufacturing of parts with additional functionalities and lower weight, in a shorter time than conventional processes. Several AM technologies are now on the market. Selective Laser Melting (SLM) [3] and Electron Beam Melting (EBM) [4] are two of them [5]. According to ISO/ASTM 52900, both are powder bed fusion processes. This means that "thermal energy selectively fuses regions of a powder bed" [1]. Contrary to the SLM process, EBM manufacturing is performed at elevated temperatures close to $700^{\circ} \mathrm{C}$ which reduces residual stresses due to temperature gradients and local cooling rates [6]. In the very recent years, numerous alloys were processed by SLM and/or EBM, among them titanium alloys with an emphasis on Ti-6Al-4V [10]. This alloy is commonly used in the aerospace and bioengineering industries because of its good mechanical properties, low density, and good corrosion resistance. Therefore, Ti-6Al-4V obtained by SLM or EBM was already studied with a particular focus on the obtained microstructures and static tensile properties. 
The microstructure of Ti-6Al-4V specimens show generally an orthotropic microstructure with prior $\beta$ grains oriented in the manufacturing direction $[7,8]$. At a higher magnification, SLM samples show a martensitic structure with $\alpha^{\prime}$ acicular grains [9] while EBM samples possess a lamellar microstructure composed of $\alpha$ grains [10]. After a Hot Isostatic Pressing (HIP) treatment, SLM specimens show the same lamellar structure as the one obtained with EBM, but with thicker grains [11]. The tensile properties of such alloys are generally above the specification coming from ASTM F2924 standard [12] and are similar to wrought specimens, except for the SLM ductility $[15,16,10]$. A very low anisotropy is generally observed when horizontal and vertical manufacturing directions are compared except also for the ductility in the SLM case $[15,9]$.

However, relatively few data are available on fatigue properties of Ti-6Al-4V specimens obtained by EBM and/or SLM and more particularly, the effect of very important parameters as the manufacturing direction, roughness and heat treatments are not deeply analyzed. One can note that improved surface quality by decreasing roughness or machining appears to improve fatigue [17-21] as a HIP treatment also does $[22,23]$ and no major effect of the manufacturing direction is observed $[17,23]$. However, to our knowledge, very few studies are trying to compare the effect of different AM processes on fatigue properties. One can cite the work of Zhai et al. [24] with a comparison between LENS and EBM processes and the recent study of Günther et al. [25] which compares SLM and EBM processes but in the Very High Cycle Fatigue regime. 
In this article, the fatigue properties of Ti-6Al-4V specimens, built by both SLM and EBM processes, are presented and compared. The influence of the process type, the manufacturing direction, a surface machining and a HIP heat treatment are discussed for both processes. Moreover, the mechanisms involved in crack initiation are analysed through post-mortem micrographs systematically performed on all broken specimens. From this analysis, different critical situations are distinguished.

\section{Materials and methods}

Fatigue test specimens made of pre-alloyed powder of Ti-6Al-4V were processed using SLM and EBM and correspond to the geometry described in Figure 1. The chemical composition of the Ti-6Al-4V corresponds to the ASTM F2924 standard [12] which is given in Table 1. The SLM specimens were built on a SLM 250HL machine with a layer thickness of $50 \mu \mathrm{m}$. These specimens were stress relieved at $640^{\circ} \mathrm{C}$ during 4 hours. The EBM specimens were built on an Arcam A2 machine, also with a layer thickness of $50 \mu \mathrm{m}$ but they were not stress relieved as the EBM machine room is maintained at $680^{\circ} \mathrm{C}$. It is largely accepted that residual stresses are negligible in this case. A description of both machines can be found in [13]. 96 cylindrical specimens were built in total, 12 specimens for each parameter as shown in Table 2. The manufacturing direction is designated according to ISO/ASTM 52921 [26] and is described in Figure 1. 12 specimens for each process 
had their surface left as-built. Roughness has not been measured on each of these fatigue specimens but on specimens obtained in the same condition. For SLM, the typical arithmetic roughness was found to be $15-25$ micrometers whereas it is $20-35$ micrometers for EBM. The others were machined and then polished by tribofinishing leading to a surface roughness $R a \leq 0.2 \mathrm{~mm}$. 12 specimens for each process were treated with a HIP treatment at $920^{\circ} \mathrm{C}$ under 1020 bar during 2 hours.

As shown in $[21,25]$, typical defects observed in a Ti-6Al-4V alloy manufactured by a powder-bed additive manufacturing process are: (i) the as-built roughness of the surface, which can also be associated to surface defects (unmelted zone on surface, open porosities), (ii) internal unmelted zones, (iii) internal porosities, generally smaller than the unmelted zones as associated to untrapped gazes. Therefore, the effect of an initial polishing treatment conducts to a decrease of the surface roughness value. The machining process conducts to the elimination of this initial roughness but however, it can also conducts to the emergence of initial sub-surface defects (porosities and/or unmelted zones). Finally, as it is shown in the literature, HIP has an effect on the mechanical properties of parts produced by additive manufacturing (see [15]). For SLM process, HIP treatment decreases the ultimate tensile stress and yield strength and improves ductility and fatigue properties. Indeed, HIP reduces the size of the defects, which is beneficial for fatigue. It also modifies the microstructure, going from an initial martensitic microstructure to a lamellar one [11]. In the case of EBM process, the fatigue properties are improved by HIP because of the reduction of the defect size, but the tensile properties are not modified 


\begin{tabular}{|c|c|c|c|c|c|c|c|c|}
\hline Element & $\mathbf{T i}$ & $\mathbf{A l}$ & $\mathbf{V}$ & $\mathbf{O}$ & $\mathbf{N}$ & $\mathbf{C}$ & $\mathbf{H}$ & $\mathbf{F e}$ \\
\hline weight \% & rest & $5.5-6.75$ & $3.5-4.5$ & $<0.2$ & $<0.05$ & 0.08 & $<0.015$ & 0.3 \\
\hline
\end{tabular}

Table 1

material composition given in ASTM F2924 standard [12].

\begin{tabular}{|c|c|c|c|c|c|}
\hline $\begin{array}{l}\text { Process } \\
\text { / Machine }\end{array}$ & $\begin{array}{c}\text { Manufacturing } \\
\text { direction }\end{array}$ & $\begin{array}{l}\text { Number of } \\
\text { specimens }\end{array}$ & $\begin{array}{l}\text { Thermal } \\
\text { treatment }\end{array}$ & $\begin{array}{l}\text { Surface } \\
\text { finishing }\end{array}$ & Total \\
\hline \multirow{2}{*}{ SLM / } & $\mathrm{Z}$ & 12 & $640^{\circ} \mathrm{C} / 4 \mathrm{~h}$ & Polishing & \multirow{4}{*}{48} \\
\hline & $X Y$ & 12 & $640^{\circ} \mathrm{C} / 4 \mathrm{~h}$ & Polishing & \\
\hline \multirow{2}{*}{$\begin{array}{l}250 \\
\text { HL }\end{array}$} & $\mathrm{Z}$ & 12 & $640^{\circ} \mathrm{C} / 4 \mathrm{~h}$ & None & \\
\hline & $\mathrm{Z}$ & 12 & $640^{\circ} \mathrm{C} / 4 \mathrm{~h}+\mathrm{HIP}$ & Polishing & \\
\hline \multirow{3}{*}{$\begin{array}{l}\text { EBM } \\
\text { / AR- } \\
\text { CAM }\end{array}$} & $\mathrm{Z}$ & 12 & None & Polishing & \multirow{4}{*}{48} \\
\hline & $X Y$ & 12 & None & Polishing & \\
\hline & Z & 12 & None & None & \\
\hline & $\mathrm{Z}$ & 12 & HIP & Polishing & \\
\hline
\end{tabular}

Table 2

list of fatigue tested specimens.

as the initial microstructure is already a lamellar one [14]. 


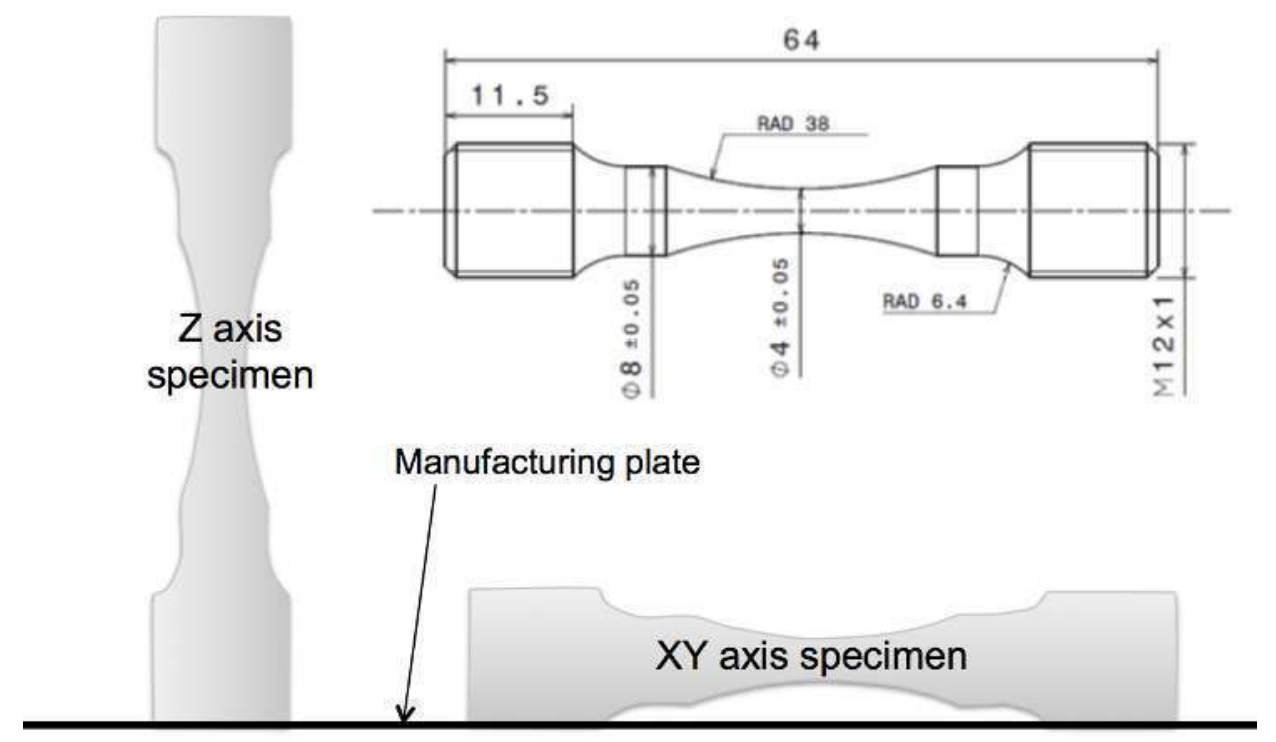

Fig. 1. geometry of the fatigue test specimens.

\begin{tabular}{|c|c|c|c|c|c|}
\hline Process & Heat treatment & $\mathbf{E}(\mathbf{G P a})$ & $\sigma_{\mathbf{y}}(\mathbf{M P a})$ & $\sigma_{\mathbf{u}}(\mathbf{M P a})$ & $\mathbf{A} \%$ \\
\hline ASTM [15] & - & - & 825 & 895 & 10 \\
\hline SLM & $640^{\circ} \mathrm{C} / 4 \mathrm{~h}$ & 127 & 961 & 1032 & 2.7 \\
\hline EBM & - & 119 & 970 & 1045 & 10.9 \\
\hline
\end{tabular}

Table 3

mean values of static properties of the studied alloy compared to ASTM F2924 [15]: E describes the Young modulus, $\sigma_{y}$, the yield strength, $\sigma_{u}$, the ultimate stress and A\% the ductility in $\%$. These data are obtained in the $\mathrm{Z}$ manufacturing direction (see Figure 1) and after machining.

Initially, static tensile tests were conducted on similar specimens and the mechanical properties obtained in the $\mathrm{Z}$ manufactured direction are given in the table 3 and are compared to the ASTM F2924 [15]. High cycle fatigue tests were performed ac- 
cording to ISO 1099 [27]. Pure reversed stress controlled loading was applied with a constant stress amplitude and a loading ratio $\mathrm{R}=-1$. An Amsler vibrophore was used with a frequency between 85 and $96 \mathrm{~Hz}$. Some specimens were loaded with a stress amplitude above $700 \mathrm{MPa}$. In these cases, the frequency was decreased to $20 \mathrm{~Hz}$ to prevent the specimens from self-heating. The fatigue tests were conducted until the failure of the specimen or when attaining $10^{7}$ cycles. After the tests, the crack initiation area were analyzed regarding post-mortem micrographs systematically performed on all broken specimens using a Nachet Vision optical microscope and also an Hitachi S-3600N scanning electronic microscope.

\section{Fatigue lifetimes}

In this part, the fatigue test results obtained with the different parameters are presented in classical S-N curves form. In the S-N curves, all the stresses shown are divided by the same constant value in order to get relative ones, permitting however systematic analysis and comparisons between parameters and/or processes. The maximal stress is chosen in order to allow comparisons with [28]. In Figure 2, a comparison between vertical building direction $(\mathrm{Z})$ and horizontal one $(\mathrm{XY})$ is done for both SLM and EBM processes. A relatively large scatter is observed, particularly in the XY direction but nevertheless, the results displayed in Figure 2 show that this XY direction is mainly associated to the more important lifetimes for both processes, even if the effect is moderate. This building directions have already 
been evaluated for static properties and seem to have an effect on the ductility in the SLM case (see $[15,9])$. To our knowledge, it seems that no systematic evaluation has already been conducted in fatigue for these two processes.

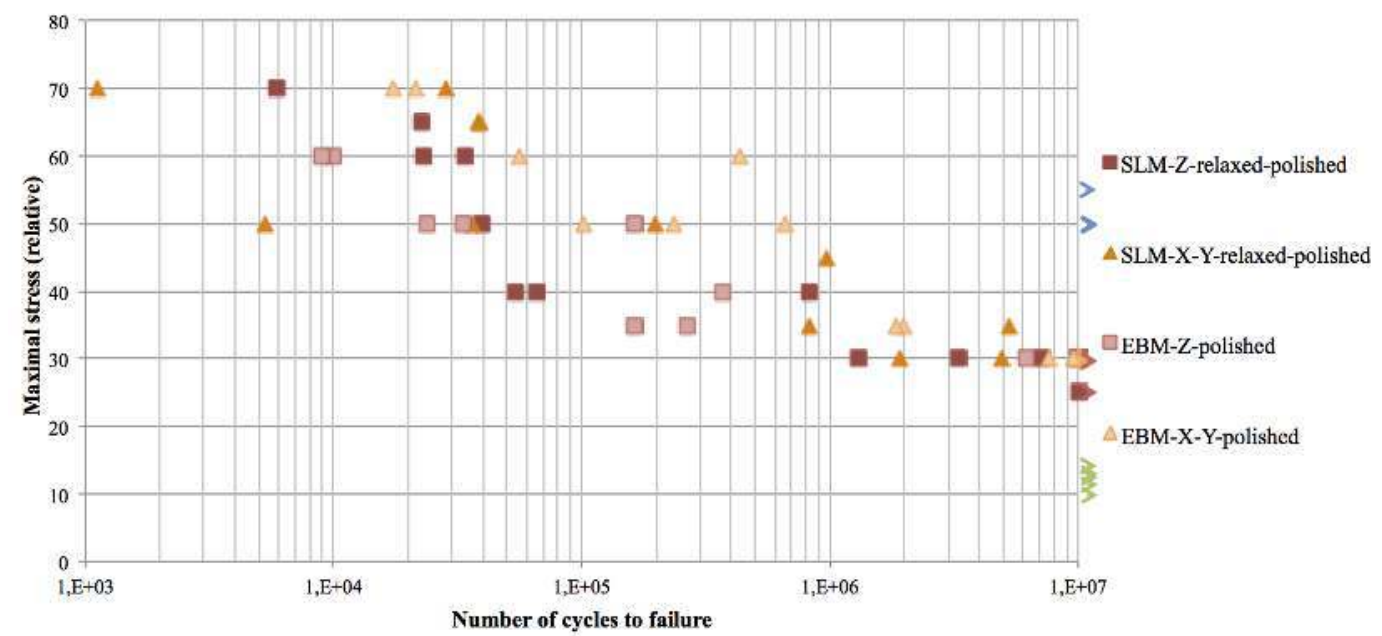

Fig. 2. comparison between vertical building direction (Z) and horizontal one (XY) for both SLM and EBM processes.

In Figure 3 a comparison between as-built and machined test specimens is done, which shows the important effect of roughness on fatigue lifetime, as already shown in [17-21]. Machining and polishing test specimens drastically improve the fatigue strength for both processes with the same impact whatever the lifetime.

In Figure 4 the effect of these machining and polishing steps are then compare to specimens submitted to an additional HIP treatment. This last one has also an important positive impact on the fatigue lifetime and this effect is more pronounced for longer lifetimes.

All these results are compared in Figure 5 to tendencies extracted from [28] obtained by casting and wrought processes and for which load ratio is not precise. 


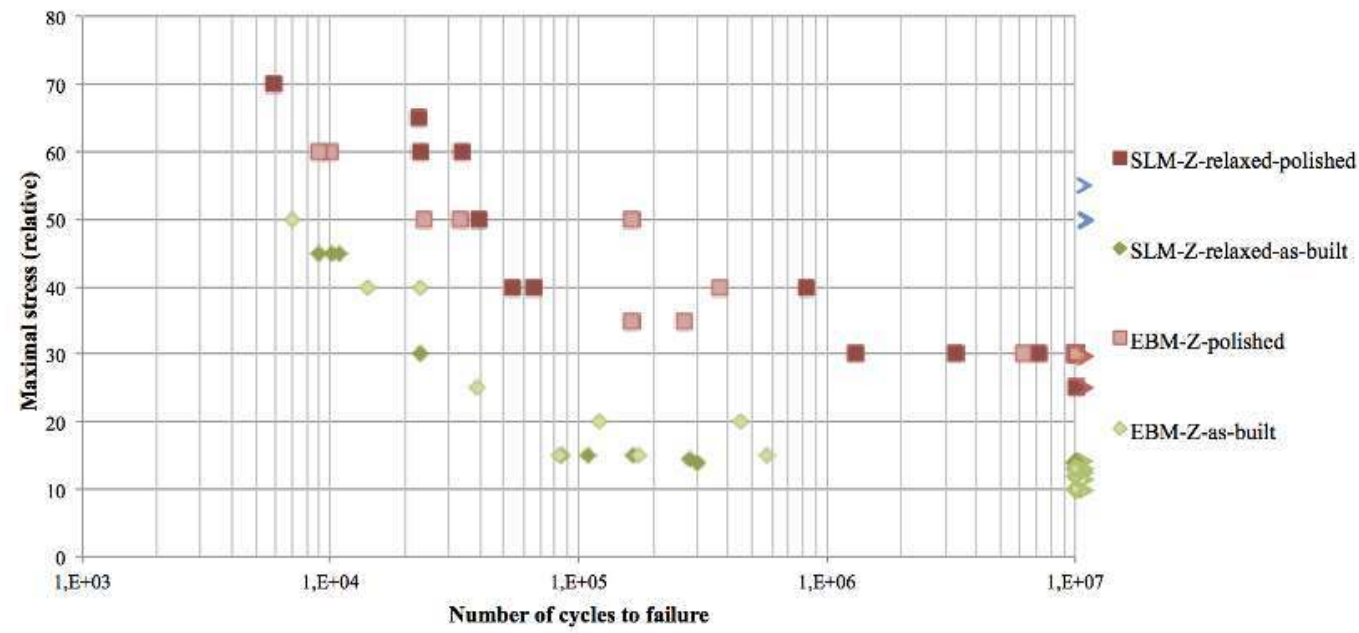

Fig. 3. comparison between as-built and machined test specimen for both SLM and EBM processes.

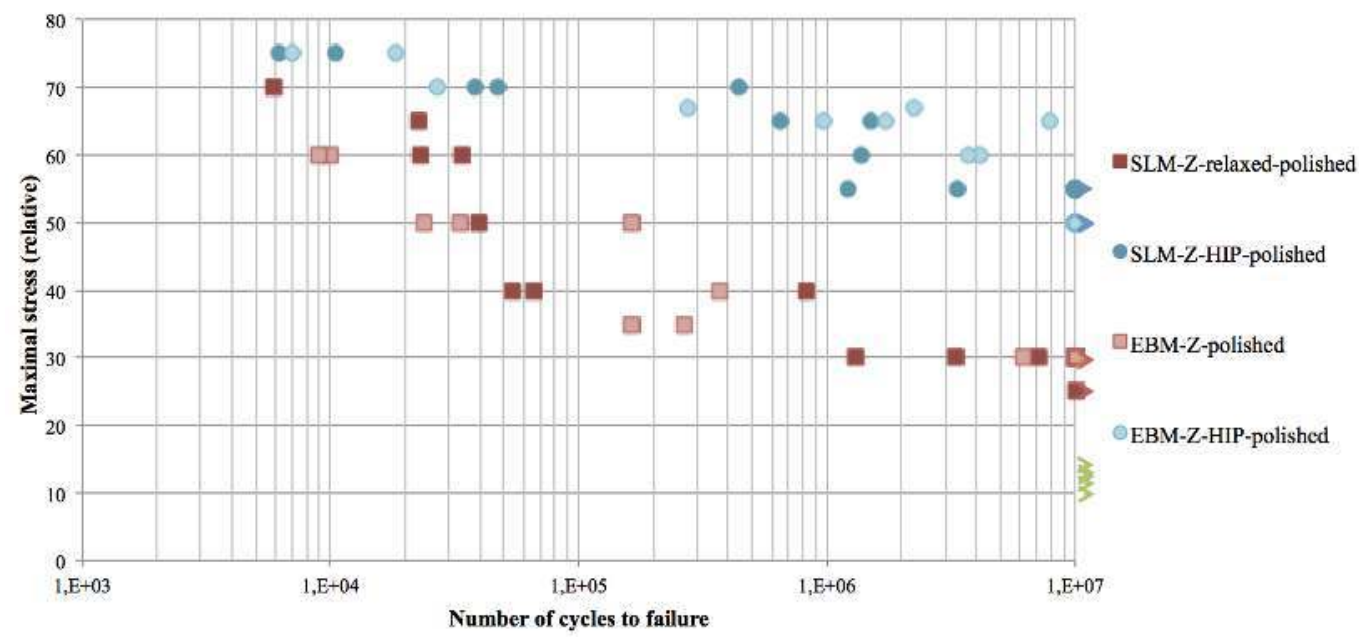

Fig. 4. effect of machining and polishing steps compared to specimens submitted to an additional HIP treatment for both SLM and EBM processes.

The results from reference [28] were placed in this normalised graph by dividing them also by the same constant as for the others S-N curves. This figure enables to summarize all the results and observations and one could underline that: (i) machining and polishing improve the fatigue properties, i.e. the stress amplitude for $10^{7}$ number of cycles, of about $100 \%$, (ii) performing an HIP treatment improves 
again the fatigue properties of about $80 \%$, (iii) the effect of the manufacturing direction is more difficult to observe, but XY specimens seems to have slightly better fatigue properties than $\mathrm{Z}$ specimens and (iv) after surface polishing, fatigue properties are at the same level of those obtained for a classical casting process and even wrought samples after HIP treatment. The last important conclusion is that no major effect of the additive manufacturing process (EBM versus SLM) can be observed in all these results : whatever the condition (as-built, machining, Z or XY and HIP), specimens obtained by EBM and SLM have similar lifetimes, regarding the scatter associated to the experimental results.

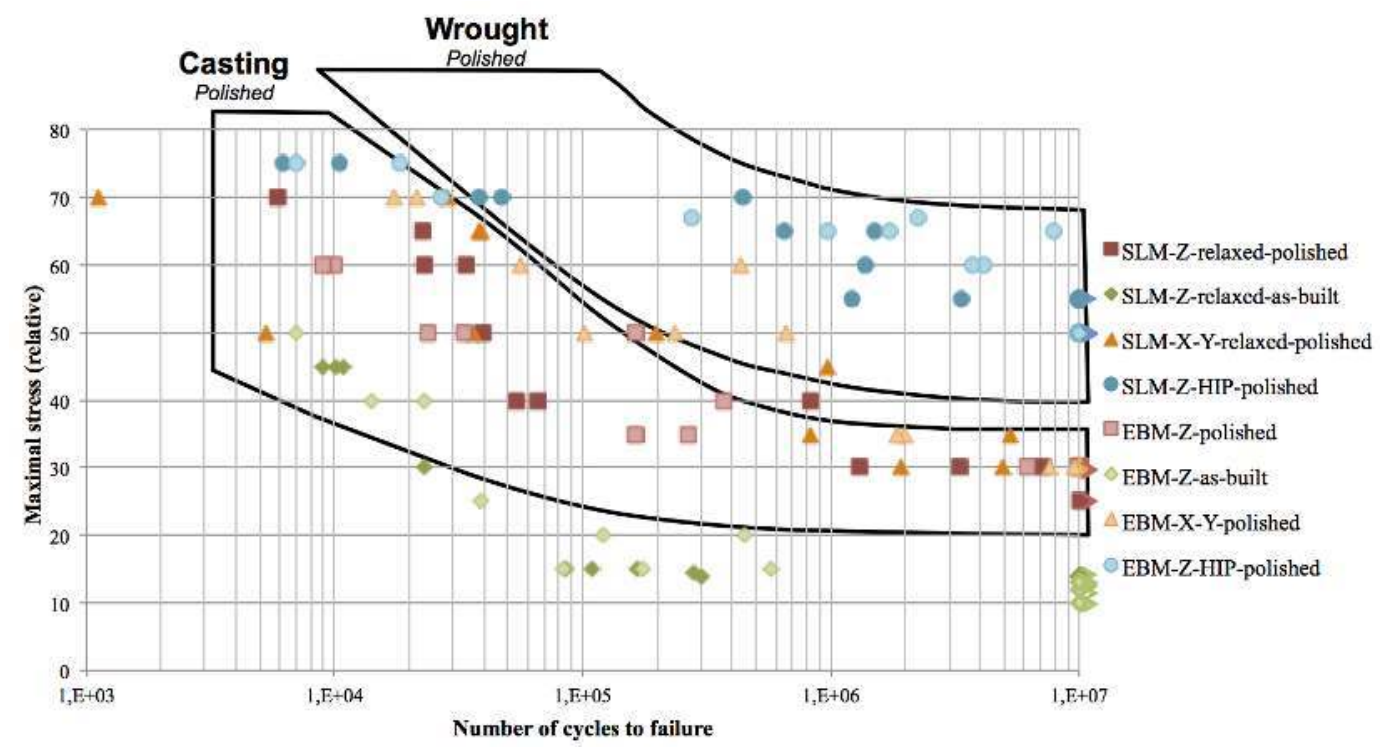

Fig. 5. comparison of fatigue lifetime obtained for both SLM and EBM processes with more classical casting and wrought processes (tendencies extracted from [28]).

\section{Crack initiation mechanisms}

As already stated, typical defects observed in this titanium alloy with these pro- 
cesses are: (i) the as-built roughness of the surface, which can also be associated to surface defects (unmelted zone on the surface, open porosities), (ii) internal unmelted zones, (iii) internal porosities, generally smaller than the unmelted zones as associated to untrapped gazes. After the tests, crack initiation areas were analysed regarding post-mortem micrographs systematically performed on all broken specimens. Different types of defects were identified to be at the origin of crack initiations and are shown on Figure 6. These defects are similar to those presented in [25]. Figures $6 \mathrm{a}$ and $6 \mathrm{~b}$ correspond to small internal defects, i.e residual small porosities, residual small unmelted zones after HIP treatment (Figure 6a) or $\alpha$ phase (Figure 6b) as shown in [25]. In fact, as already stated, the effect of HIP treatment is to close most of the initial defects. In this case, it has been shown [25] that small residual porosities as well as $\alpha$-phase can be also responsible of the fatigue crack initiation. Internal unmelted zones, as observed in Figures $6 \mathrm{c}$ and $6 \mathrm{~d}$ are typical to these powder-bed processes. The orientations of these unmelted zones are parallel to the layers. Then, depending on the building directions, these unmelted zones can be parallel (see Figure 6d) or perpendicular (see Figure 6d) to the loading direction. Cracks can also initiate from the surface, due: (i) to the initial as-built roughness or (ii) from initially sub-surface defects, which intersect the surface after the machining and polishing steps. Indeed, even if the objective of a surface machining is the elimination of the initial roughness, it can also conducts to the emergence of initially sub-surface defects (porosities and/or unmelted zones) on the surface. All the broken specimens surfaces were observed and analysed and the crack initiation associated defects were determined following the previ- 


\begin{tabular}{|c|c|c|c|}
\hline & Surface & Internal unmelted zones & Small internal defects \\
\hline As-built & $\mathbf{1 0}$ & 0 & 3 \\
XY and Z polished & 4 & $\mathbf{2 5}$ & 12 \\
HIP-polished & 5 & 0 & $\mathbf{1 0}$ \\
\hline
\end{tabular}

Table 4

types of defect conducting to crack initiation (surface, internal unmelted zones, small internal defects) associated to the post-treatment parameters (as-built, $\mathrm{XY}$ and $\mathrm{Z}$ polished, HIP-polished) whatever the process (SLM, EBM).

ous classification (surface, internal unmelted zones, small internal defects). Results are synthesized in Figure 7 where each type of defect conducting to crack initiation has been associated to a specific symbol. One can clearly distinguish three main domains: (i) shorter lifetime are mainly associated to crack initiations on surface defects, (ii) intermediate lifetime to internal unmelted zone and (iii) longer lifetime to small internal defects, even if a relative scatter is observed. In order to quantify this observation, in Table 4, types of defect conducting to crack initiation (surface, internal unmelted zones, small internal defects) have been associated to the post-treatment parameters (as-built, XY and Z polished, HIP-polished) whatever the process (SLM, EBM) as the process seems to have a minor effect on the fatigue properties. This table confirms these three domains. 

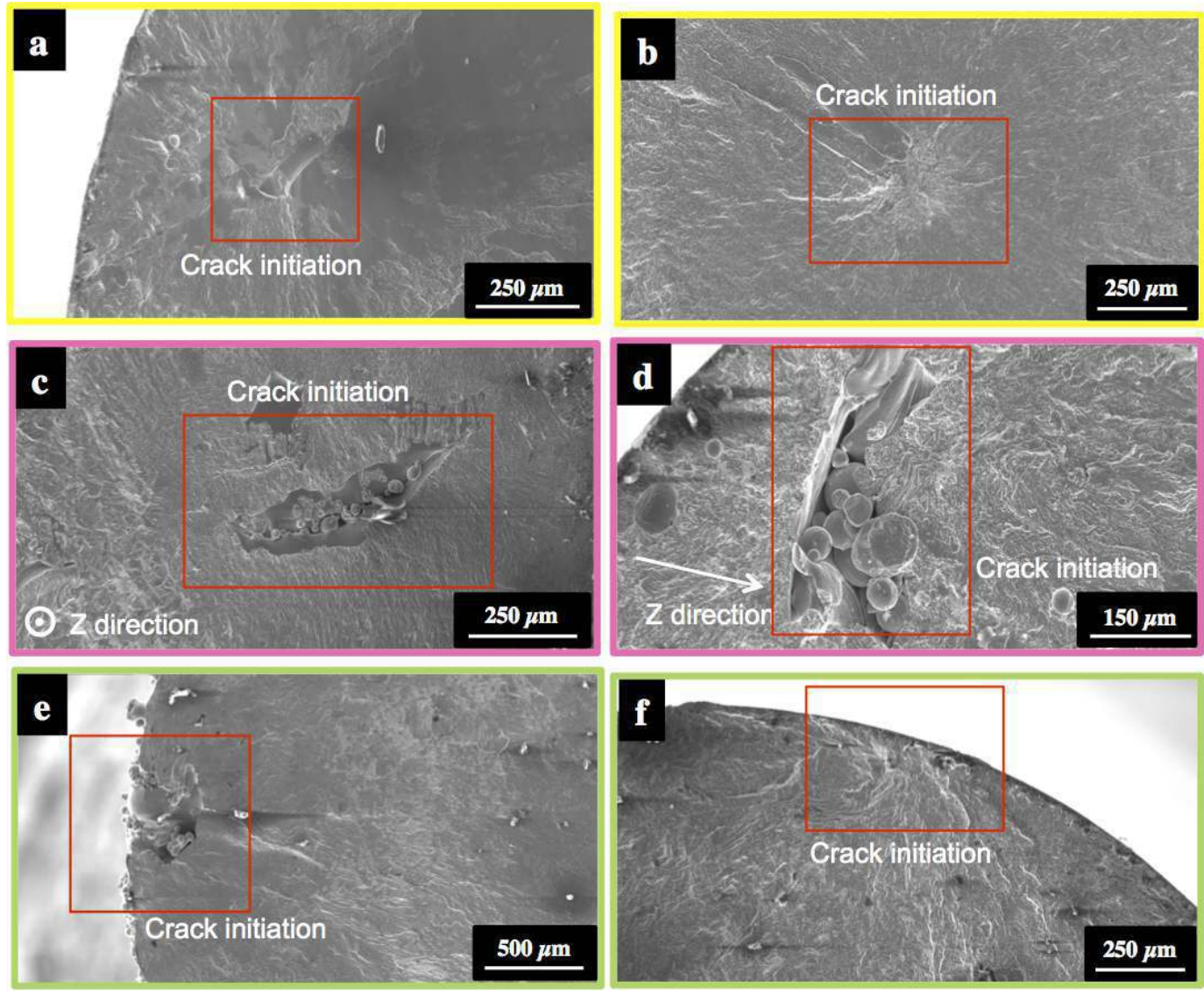

Fig. 6. different types of defects identified as the crack initiation zone: small defects and/or porosities on a) EBM, Z-direction, polished, $\sigma_{\max }=50 \mathrm{MPa}, N_{f}=163000$ cycles and b) EBM, Z-direction, HIP, polished, $\sigma_{\max }=65 \mathrm{MPa}, N_{f}=1721160$ cycles, unmelted zones on c) SLM, Z-direction, polished, $\sigma_{\max }=30 \mathrm{MPa}, N_{f}=7128212$ cycles and d) EBM, XZ-direction, polished, $\sigma_{\max }=30 \mathrm{MPa}, N_{f}=9610224$ cycles and surface defects on e) SLM, Z-direction, as-built, $\sigma_{\max }=14.5 \mathrm{MPa}, N_{f}=278380$ cycles and f) EBM, Z-direction, HIP, polished, $\sigma_{\max }=60 \mathrm{MPa}, N_{f}=4123148$ cycles

\section{Discussion}

The criticality of the defects as described in the previous section can now be discussed. As classically observed in fatigue, a relative scatter is observed in Fig- 


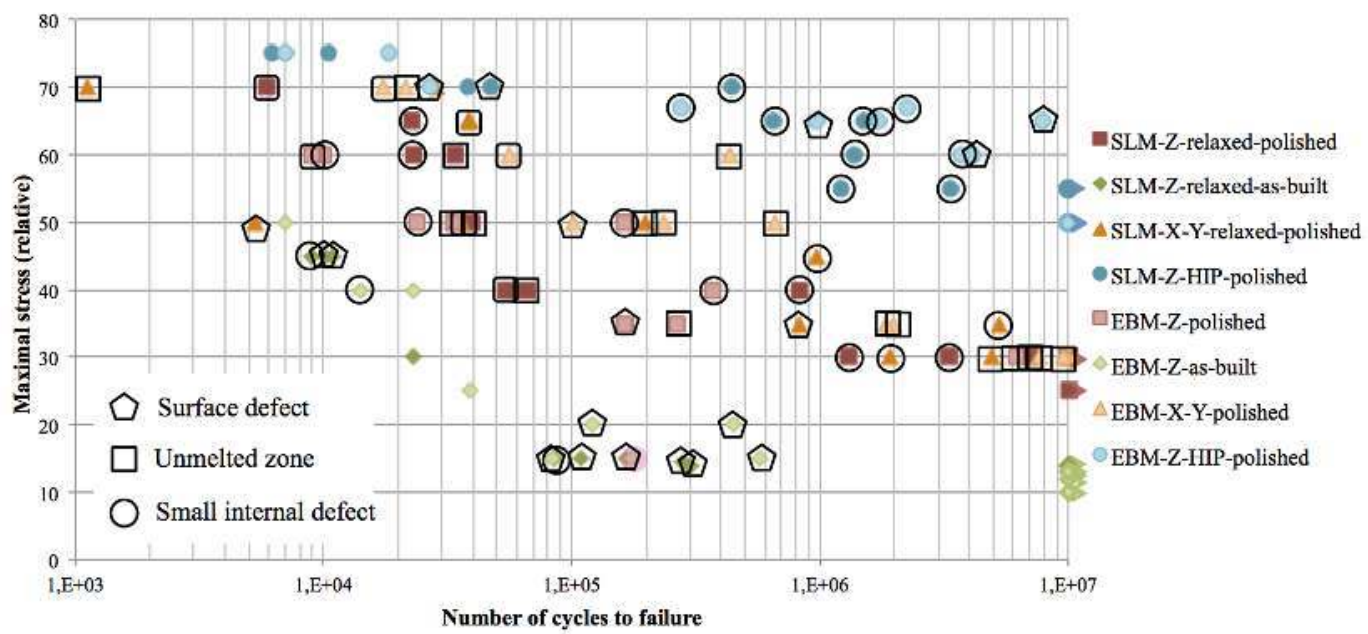

Fig. 7. influence of the defects on the lifetimes obtained for both EBM and SLM processes. A green point corresponds to a crack initiation on a surface defect, a pink one, on a lack of fusion zone and a yellow one, on porosities.

ure 7 and is confirmed in Table 4. Despite this scatter, it is observed that as-built specimens, which posses the highest roughness, generally conduct to the shorter lifetimes domain with a crack initiating from the surface. This is a common observation in fatigue that crack initiates generally from the surface. But this conclusion must be relativised when sub-surface or internal defects (as porosities or unmelted zones) are present as in the present case or also in the case of casting process (as porosities or shrinkages) [33].

Therefore, when machining and polishing as-built specimens, surface defects are mostly removed. As they are the most critical defects, lifetimes are generally larger than for as-built specimens as already shown in [17-21]. However, one can also observed in Figure 7 machining and polishing specimens with shorter lifetimes. In fact, surface machining can conduct to the emergence of initially internal defects 
(porosities and/or unmelted zones) on the surface, which increases their criticality.

But beyond such particular cases, the intermediate domain in Figure 7 corresponds mainly to crack initiation on unmelted zones as soon as the specimens are machined and polished, as clearly shown in Table 4. Such unmelted zones are observed in the bulk or in sub-surface areas. As the position of the defects respectively to the surface is an influencing parameter on the crack initiation time, as shown in the case of shrinkage in casting alloys $[33,34]$, this has an impact on the criticality and the lifetimes. In the case of unmelted zones, one can observe in Figure 7 that the fatigue properties are qualitatively slightly better for the specimens built in the $\mathrm{XY}$ direction. Indeed, as unmelted zones preferably appear between two layers, the orientation of such defect is mainly perpendicular to the building direction. Then, for the specimens built in the XY direction, unmelted zones are certainly mainly parallel to the loading direction, which is qualitatively less critical than to be perpendicular to the loading direction in the case of the $\mathrm{Z}$ building direction. This could explain the observed difference in fatigue properties between XY and Z-building directions but unfortunately, this assumption has not been confirmed by experimental observations. Complementary tests could be necessary with 3D realtime analysis.

Finally, the last domain with the longer lifetimes correspond mostly to HIP specimens, as HIP is known to reduce the size of most of the defects (porosities or unmelted zones). Also in this later case, a relative scatter is observed in lifetimes and Table 4 shows that this is due to residual surface defects. 
From these analysis based on post-mortem observations as in [21], and despite a relative observed scatter, the main conclusions are that surface defects are generally more critical in fatigue than unmelted zones which are more critical than small bulk defects as porosities or $\alpha$-phase. Moreover, the study also shown that the type of defects as described previously are the same for both processes. Therefore, EBM and SLM, fatigue properties are quite similar as confirmed in [24]. In this work, Günther et al. are conducting fatigue tests in the Very High Cycle regime and it can be observed that for lifetime greater that $10^{7}$ cycles, internal defects are mostly associated to the crack initiation process where surface defects are the dominant mechanisms for lifetimes lower than $10^{7}$ cycles. These observations are consistent with the results obtained in the present study and show that crack initiation mechanisms depend also on the fatigue regime.

However, in this study, as in other ones as [21], only post-mortem observations were conducted and no quantification of defects size and/or morphology were done, which could improve the proposed qualitative analysis. In fact, in the case of casting alloys, it has been shown that a simple 2D analysis (size, morphology) from data extracted from surface images of such complex 3D defects is generally not sufficient to understand and quantify their impact on crack initiation mechanisms and on lifetime, even if some statistical corrections are possible [30,31]. Therefore, a systematic 3D quantitative analysis of the specimens microstructure by CTtomography (as conducted in [32]) could be direct a direct perspective of this work, associated to in-situ fatigue tests as in[33-35]. 


\section{Conclusion}

In summary, fatigue tests have been performed on additive manufactured specimens with two powder bed fusion processes (EBM and SLM). The effects of manufacturing direction, HIP treatment and roughness have been observed and analyzed according to micrographs performed on each broken specimens. Three types of defects have been observed and could be sorted from the most to the less critical: surface defects, unmelted zones and small internal defects. Machining and polishing steps improve the fatigue properties by removing surface defects and initial roughness. HIP treatment improves fatigue by decreasing the defects size. The effect of the manufacturing direction depends on the presence of unmelted zones. Finally, the effect of the process - EBM and SLM - seems to be negligible because defects are of the same type in both cases. Depending on the post-treatment applied to the specimens, parts coming from additive manufacturing with these both processes possess the similar fatigue properties than cast or wrought parts. The qualitative conclusions about crack initiation mechanisms could be challenged by performing 3D CT-tomography associated to in situ tensile tests on several specimens; realtime analysis could then be performed in order to observe the crack initiation and propagation phenomenon as already done on casting alloys [33,32,34,35]. 


\section{Acknowledgement}

The authors acknowledge Astrid Tezenas and Yannick Cadoret for fruitfull discussion during this study.

\section{References}

[1] International Organization for Standardization/American Standard for Testing and Material, ISO/ASTM 52900 Additive manufacturing - General principles Terminology, 2015.

[2] P. Reeves, Additive Manufacturing - A supply chain wide response to economic uncertainty and environmental sustainability, Econolyst Limited, The Silversmiths, Crown Yard, Wirksworth, Derbyshire, DE4 4ET, UK, 2009.

[3] J.-P. Kruth, G. Levy, F. Klocke and T. Childs, Consolidation phenomena in laser and powder-bed based layered manufacturing, CIRP Annals-Manufacturing Technology, vol. 56, no. 2, pp. 730-759, 2007.

[4] L. E. Murr, E. Esquivel, S. Quinones, S. Gaytan, M. Lopez, E. Martinez and R. Wicker, Microstructures and mechanical properties of electron beam-rapid manufactured Ti-6Al-4V biomedical prototypes compared to wrought Ti-6Al-4V, Materials Characterization, vol. 60, no. 2, pp. 96-105, 2009.

[5] K. P. Karunakaran, A. Bernard, S. Suryakumar, L. Dembinski and G. Taillandier, Rapid manufacturing of metallic objects, Rapid Prototyping Journal, vol. 18, no. 4, pp. 264280, 2012. 
[6] H. Weiwei, J. Wenpeng, L. Haiyan, T. Huiping, K. Xinting and H. Yu, Research on preheating of titanium alloy powder in electron beam melting technology. Rare Met. Mater. Engng., vol. 40, pp. 2072-2075, 2011.

[7] B. Vrancken, L. Thijs, J.-P. Kruth and J. Van Humbeeck, Heat treatment of Ti6Al4V produced by Selective Laser Melting: Microstructure and mechanical properties, Journal of Alloys and Compounds, vol. 541, pp. 177-185, 2012.

[8] A. Antonysamy, J. Meyer and P. Prangnell, Effect of build geometry on the $\beta$-grain structure and texture in additive manufacture of Ti-6Al-4V by selective electron beam melting, Materials Characterization, vol. 84, pp. 153-168, 2013.

[9] T. Vilaro, C. Colin and J.-D. Bartout, As-fabricated and heat-treated microstructures of the Ti-6Al-4V alloy processed by selective laser melting, Metallurgical and Materials Transactions A, vol. 42, no. 10, pp. 3190-3199, 2011.

[10] H. Rafi, N. Karthik, H. Gong, T. Starr and B. Stucker, Microstructures and Mechanical Properties of Ti6Al4V Parts Fabricated by Selective Laser Melting and Electron Beam Melting, Journal of Materials Engineering and Performance, vol. 22, no. 12, pp. 38723883, 2013.

[11] G. Kasperovich and J. Hausmann, Improvement of fatigue resistance and ductility of Ti6Al4V processed by selective laser melting, Journal of Materials Processing Technology, vol. 220, pp. 202-214, 2015.

[12] American Standard for Testing and Material International, ASTM F2924 - Standard Specification for Additive Manufacturing Titanium-6 Aluminum-4 Vanadium with Powder Bed Fusion, 2014. 
[13] T. Wohlers, Additive Manufacturing and 3D Printing State of the Industry: Annual Worldwide Progress Report, 2013.

[14] M. Svensson, Material Properties of EBM Manufactured Ti6Al4V and Ti6Al4V ELI under raw and HIP conditions, Arcam AB, data obtained with an Arcam EBM S12 system, 2008.

[15] C. Qiu, N. J. Adkins and M. M. Attallah, Microstructure and tensile properties of selectively laser-melted and of HIPed laser-melted Ti-6Al-4V, Materials Science and Engineering: A, vol. 578, pp. 230-239, 2013.

[16] H. Gong, K. Rafi, H. Gu, G. Janaki Ram, T. Starr and B. Stucker, Influence of defects on mechanical properties of Ti-6Al-4V components produced by selective laser melting and electron beam melting, Materials and Design, vol. 85, pp. 545-554, 2015.

[17] K. Rafi, N. Karthik, T. Starr and B. Stucker, Mechanical property evaluation of Ti-6Al-4V parts made using Electron Beam Melting, in Solid Freeform Fabrication Symposium, Austin, Texas, USA, 2012.

[18] E. Wycisk, C. Emmelmann, S. Siddique and F. Walther, High Cycle Fatigue (HCF) Performance of Ti-6Al-4V Alloy Processed by Selective Laser Melting, Advanced Materials Research, pp. 134-139, 2013.

[19] A. Fatemi, R. Molaei, S. Sharifimehr, N. Shamsaei and N. Phan, Torsional fatigue behavior of wrought and additive manufactured Ti- $6 \mathrm{Al}-4 \mathrm{~V}$ by powder bed fusion including surface finish effect. International Journal of Fatigue, vol. 99, pp. 187-201, 2017.

[20] A. Fatemi, R. Molaei, S. Sharifimehr, N. Phan and N. Shamsaei, Multiaxial fatigue 
behavior of wrought and additive manufactured Ti-6Al-4V including surface finish effect. International Journal of Fatigue, vol. 100, pp. 347-366, 2017.

[21] S. Bagehorn, J. Wehr and H. J.Maier, Application of mechanical surface finishing processes for roughness reduction and fatigue improvement of additively manufactured Ti-6Al-4V parts. International Journal of Fatigue, vol. 102, pp. 135-142, 2017.

[22] M. Benedetti, M. Cazzoli, V. Fontanari and M. Leoni, Fatigue limit of Ti6Al4V alloy produced by Selective Laser Sintering, in 21st European Conference on Fracture, Catania, Italy, 2016.

[23] X. Zhao, S. Li, M. Zhang, Y. Liu, T. B. Sercombe, S. Wang, Y. Hao, R. Yang and L. E. Murr, Comparison of the microstructures and mechanical properties of Ti-6Al-4V fabricated by selective laser melting and electron beam melting, Materials and Design, vol. 95, pp. 21-31, 2016.

[24] Y. Zhai, H. Galarraga and D.A. Lados, Microstructure, static properties, and fatigue crack growth mechanisms in Ti-6Al-4V fabricated by additive manufacturing: LENS and EBM. Eng. Fail. Anal., vol. 69(C), pp. 3-14, 2016.

[25] J. Günther, D. Krewerth, T. Lippmann, S. Leuders, T. Tröster, A. Weidner, H. Biermann and T. Niendorf, Fatigue life of additively manufactured Ti-6Al-4V in the very high cycle fatigue regime, International Journal of Fatigue, vol. 94, pp. 236-245, 2017.

[26] International Organization for Standardization/American Standard for Testing and Material International, ISO/ASTM 52921 - Standard terminology for additive manufacturing - Coordinate systems and test methodologies, 2013. 
[27] International Organization for Standardization, ISO 1099 - Metallic materials - Fatigue testing - Axial force-controlled method, 2006.

[28] M. J. Donachie, Titanium: A Technical Guide, 2nd Edition, ASM International, 2000.

[29] H. Gong, K. Rafi, T. Starr and B. Stucker, Effect of defects on fatigue tests of as-built Ti-6Al-4V parts fabricated by selective laser melting, in Solid Freeform Fabrication Symposium, Austin, Texas, USA, 2012.

[30] F. Szmytka, N. Limodin, L. Wang, P. Osmond, J. Adrien, E. Charkaluk, and JY. Buffiere, Probabilistic thermal-mechanical fatigue criterion for lost foam casting aluminium alloys based on 2D/3D porosities distribution, MATEC Web of conferences, 12, 05005, 2014.

[31] A. Cetin, A. Roiko, and M. Lind, Towards proper sampling and statistical modelling of defects, Fat. Frac. Engng. Mat. Struct., vol. 38, pp. 1056-1065, 2015.

[32] N. Limodin, A. El Bartali, L. Wang, J. Lachambre, and E Charkaluk. Application of X-ray microtomography to study the influence of the casting microstructure upon the tensile behaviour of an Al-Si alloy. Nuclear Inst. and Methods in Physics Research, B, vol. 324, pp. 57-62, 2014.

[33] J.-Y. Buffière, S. Savelli, P.H. Jouneau, E. Maire, R. Fougères, Experimental study of porosity and its relation to fatigue mechanisms of model $\mathrm{Al}$ ? $\mathrm{Si} 7 ? \mathrm{Mg} 0.3$ cast $\mathrm{Al}$ alloys, Mater. Sci. Eng., vol. 316, pp. 115?126, 2001.

[34] L. Wang, N. Limodin, A. El Bartali, J-F. Witz, R. Seghir, J-Y. Buffière, and E. Charkaluk. Influence of pores on crack initiation in monotonic tensile and cyclic loadings in lost foam casting A319 alloy by using 3D in-situ analysis. Mat. Sci. Engng. 
A, vol. 673, pp. 362?372, 2016.

[35] N. Dahdah, N. Limodin, A. El Bartali, J-F. Witz, R. Seghir, E. Charkaluk, and J-Y. Buffière. Damage investigation in A319 aluminium alloy by X-Ray tomography and digital volume correlation during in situ high temperature fatigue tests, Strain, vol. 52(4), pp. 324?335, 2016. 